\title{
ZERO, UMA OBRAFRAGMENTADA REPRESENTADA PELA VIOLÊNCIA DA DITADURA MILITAR
}

\author{
Alcione Salete Dal'AlbaPilger ${ }^{1}$ \\ Lizandro Carlos Calegari ${ }^{2}$
}

\begin{abstract}
Resumo: A proposta deste artigo é analisar a relação entre a violência e a forma no livro Zero, de Ignácio de Loyola Brandão (1975), publicado no Brasil em 1975. Considerando que o corpus de análise tematiza a violência da ditadura militar no Brasil (1964-1985), a obra está inserida nesse contexto, é engajada, representa o social. Objetiva-se mostrar a violência através de sua forma fragmentada,que representa o país daquela época por estar associada à ideia de desordem e caos, do período. A simulação de recortes de jornal, propagandas, cartazes, inscrições de banheiro, letras de música e inúmeros outros tipos de texto vão criando uma paisagem do país e seu contexto histórico social. A hipótese é a de que a mistura de gêneros, no processo de montagem cria uma metáfora para a ditadura no Brasil. A metodologia configura-se a partir de relações que estabelecemos entre ficção, história, violência e forma. Para o embasamento dessa proposta e ou abordagem, busca-se respaldo em autores como Jean Baudrillard (1991), Jaime Ginzburg (2012), Tania Pellegrini (1994-1996), Lizandro Calegari (2011).
\end{abstract}

Palavras-chave: Zero; Violência; Forma; Simulacro; Fragmentação.

Abstract: The purpose of this paper is to analyze the relation between violence and the form in the book Zero, from Ignácio de Loyola Brandão (1975), published in Brazil in 1975. Considering that the analysis corpus studies the violence of the military dictatorship in Brazil (1964-1985), the work is inserted in this context, is engaged, it represents the social. We aim to show that violence by its fragmented form, represents the country of that time to be associated with the idea of disorder and chaos, in that period. The simulation of newspaper clippings, advertisements, posters, toilet entries, song lyrics and many other types of text are creating a landscape from the country and its social historical context. The hypothesis is that the mixture of genres, in the assembly process creates a metaphor for the dictatorship in Brazil. The methodology is configured from relationships established between fiction, history, violence and form. For the basis of this proposal and either approach, we seek support in authors such as Jean Baudrillard (1991), Jaime Ginzburg (2012), Tania Pellegrini (19941996), Lizandro Calegari (2011).

Keywords: Zero; violence; form; simulation; fragmentation.

\footnotetext{
${ }^{1}$ Mestranda do Curso de Letras - URI/FW

${ }^{2}$ Orientador (UFSM/FW). Lizandro Carlos Calegari é Doutor em Letras, Literatura Brasileira pela Universidade Federal de Santa Maria (UFSM). Atualmente atuando em Cursos Livres no programa e Pós-Graduação (Mestrado) em Letras, URI, FW
} 


\section{Introdução}

"Carpe diem quamminimum crédula póstero".

(Horácio Flaco)

A epígrafe remete ao zero que é o nada no título Zero (1975), mas que aponta para o tempo presente, não ao tempo futuro, bem como ao sentimento da transitoriedade e da pequenez da vida. Portanto, a preocupação com o presente, sem projeção no futuro é uma das principais características do romance pósmoderno, na literatura. A história vivida pelos protagonistas Rosa e José, cuja temática é justamente a repressão e o desejo de liberdade, eles vivem uma relação complexa de desprezo e incontrolável desejo, que se passa durante a ditadura militar, ou seja, o mesmo período em que o livro fora escrito.

O propósito deste trabalho consiste em propor uma reflexão a respeito de alguns procedimentos literários utilizados pelo autor do aludido romance tais como a fragmentação da narrativa e a forma da representação da violência. Procura-se avaliar a forma na obra em questão sem perder de vista a perspectiva crítica que ele suscita quando associados à conjuntura social que caracteriza o Brasil nos anos 70 . Desse modo, na perspectiva de Calegari (2011) é de que se parte da premissa de que a recorrência a formas híbridas de apresentação estética não é gratuita, mas articulada de tal maneira que deixa subjacente um componente crítico em relação à realidade histórica apresentada.

A obra Zero, de Ignácio de Loyola Brandão foi publicado por força das circunstâncias políticas em 1974, na Itália. Em 1975, no Brasil, proibido pela censura por ser considerado um atentado à moral e aos bons costumes. Foi considerada a melhor obra do ano pela Fundação Cultural de Brasília. Em 1976, foi proibido de circular em todo país. Fora publicado novamente em 1979, despertando muita polêmica àquela época. Narrativa pós-moderna em construção, hipertexto que desrespeita as regras convencionais da literatura, verdadeiro documentário político.

Referente ao contexto da época ressalta-se que a ditadura militar corresponde ao período marcado pela censura, perseguição política, supressão dos direitos constitucionais, falta de democracia e repressão instalada no Brasil a partir de 31 de março de 1964 e conduzida por militares até 1985. Através da violência era 
efetivado o controle do país, a dominação dos meios de comunicação e a censura à história, à produção literária e artística. Dessa forma, a literatura buscou meios estratégicos para manifestar-se, romances-reportagens, obras de denúncia como forma de contribuir para a consciência crítica sobre o período da ditadura no Brasil.

Nestes textos, são representadas as vítimas da violência resultante das práticas de tortura e repressão, bem como os mecanismos utilizados par manter o controle social. O uso de metáforas e códigos eram recursos empregados para escapar de que a circulação do material fosse proibida pelo Governo. Dentre estas produções, destaca-se o romance Zero, de Ignácio de Loyola Brandão (1975), que caracteriza a literatura de denúncia e resistência. Propõe-se a enfatizar a violência da ditadura militar na ficção brasileira pós-64, representada no livro. Nesse sentido, a pesquisa tem o objetivo de identificar a violência no discurso do romance para entender-se a representação da ditadura militar na identidade do personagem principal José e uma reflexão referente à forma - estrutura da obra em questão.

Várias histórias que retratam o cotidiano de indivíduos que passaram pela experiência da violência no período da ditadura constituem o enredo da obra. $\mathrm{Na}$ convivência do casal José Gonçalves e Rosa Maria Lopes a violência é constate o que torna o cônjuge assaltante, assassino e partícipe do grupo "Gê", destinado a combater as práticas autoritárias.

O desajuste do indivíduo é representado através de traços, elementos gráficos evidenciados na realidade, na qual está inserido, tais como: gráficos sobre um operário chamado Pedro, ilustrações sobre o corpo humano, cardápios de lanchonetes outdoors, formas geométricas, sinais gráficos, anúncios de casamento dados sobre assaltos, jaculatórias ilustrações, trechos de músicas, notícias sobre repressão, expressões em inglês e trechos em espanhol. Isso é evidenciado na estrutura dos capítulos, os quais se constituem por fragmentos curtos, no entanto, muitas informações. Não há preocupação com a sintaxe, com a pontuação, prevalece o Discurso Indireto Livre aproxima-se à fala coloquial. Pellegrini (1994) define esse tipo de narrativa da seguinte forma:

Essa insólita maneira de escrever um romance, como quem monta (ou desmonta?) um quebra-cabeça, produziu um resultado final impressionante, em que as partes se juntam, em primeira abordagem, um todo (in)coerente, (des)harmônico, (in)verossímil, sem entretanto esconder sua característica fundamental: a 
fragmentação, o estilhaçamento, e pulverização da narrativa (PELLEGRINI, 1994, p. 128-129).

Assim, a fragmentação é a base da narrativa, estruturada por uma compilação de arquivos, notícias, documentos que representam os personagens, a cidade viva, os entornos, o mundo caótico e desordenado. Dessa forma, acredita-se ser importante investigar a história e influência das diversas formas de violência praticadas na sociedade brasileira e até avaliar a representação do impacto dessa violência na construção do romance Zero, no contexto da obra. Como observa Calegari (p.166, 2011):

[...] a produção literária de Brandão se situa dentro do período ditatorial brasileiro, iniciado em 1964 e estendido até 1985, com o término do mandato do General João Batista de Figueiredo. Nesse período conturbado, boa parte da literatura é marcada pela resistência à situação político-social em curso; pela denúncia, ora satírica, ora bem-humorada, das consequências dela decorrentes; pelo desejo de liberta- ção moral e pela literatura-reportagem ou literatura-documento, que visava a um realismo sem máscaras. Ela, em inúmeros casos, se transforma em arma de combate e ação social. Há um inimigo comum - o Governo - e há, entre vários escritores, uma constante indignação e uma vontade de mudar a situação circundante (CALEGARI, 2011, p.166).

Com isso, objetivando retratar os fatos e criticar o sistema duro e desumano vigente que imperava.

Ressalta-se que na edição comemorativa de 35 anos da Global Editora há um depoimento do autor intitulado "E se eu não tivesse tido coragem de publicar Zero naquele ano de 1974?" em que ele comenta como o livro foi se formando, a partir desses vários textos que eram censurados no jornal Última Hora, onde trabalhava na década de 60. Imaginou que tudo aquilo que não poderia ser dito, poderia ser aproveitado. Por isso a enorme variedade de textos que compõem o romance. Livro para pensar e constatar sobre o passado.

A importância deste estudo dá-se também pela sua aplicabilidade no contexto escolar na medida em que se propõe a analisar a representação acerca da violência, um assunto que precisa ser melhor discutido nos bancos escolares dado o aumento significativo da violência na sociedade atual, embora fora do contexto da ditadura militar. Justifica-se esta proposta como relevante pela necessidade de compreender e retomar o processo de violência do período ditatorial e como é representado na 
obra literária, a pesquisa para tanto, é de caráter bibliográfico. Jean Baudrillard (1991), Jaime Ginzburg (2012), Tânia Pellegrini (1994-1996),Lizandro Calegari (2011) embasam a pesquisa.

\section{A representação da violência e a forma no romance Zero, de Ignácio de Loyola Brandão} nada por detrás delas" (BAUDRILLARD, 1991, p.48)

A estrutura física de Zero (1975) é fragmentada, o narrador, em terceira pessoa, apresenta o protagonista JOSÉ, numa intertextualidade com o texto de Drummond "E agora, José"que retratam personagens marginais, simples, homem comum, no caso, José é um caçador de ratos: "José mata ratos num cinema poeira. É um homem comum, 28 anos, que come..."(p.11). Também o amigo Átila é apresentado e é importante ressaltar que não conseguira trabalhar como professor, fora sugerido por um inspetor propina para passar, então: "Atila cagou no diploma e jogou na porta do departamento de educação" (1), conforme nota de rodapé: (1) "Depois se arrependeu." (p.13), explicamos que por não pontuar o texto, a explicação torna-se pertinente. O aqui e o agora e traz a preocupação com o presente, sem projeção de futuro - um ecletismo estilístico. Além disso, as notas de rodapé oferecem um ponto de vista à parte, com o próprio autor (ou um narrador onisciente, como queira) conversando com a história e ironizando o que está sendo feito ou dito pelos personagens.

Menciona-se como exemplo que aparece logo após o título "AGUARDEM"; subtítulo: A CRIAÇÃO DE JOSÉ SEGUNDO SUA MÃE ou a formação moral de um homem, segue em texto em discurso indireto livre com passagens em itálico "Vamos comungar meu filho Venha com a mamãe para a missa Pegue o seu missalzinho Se confessou direito ontem a gente precisa ser um bom católico..." (p.39); entrecortado pela reprodução da voz da catequista, entre parênteses: (Cara séria, cabeça abaixada, respeito: disse a catequista: a primeira comunhão é o momento mais importante na vida de um católico: depois, só a morte) (p. 39) e a presença de palavras e expressões em latim nas orações e jaculatórias: “... gló ó óóóóóóóóóóó 
ria, in excelsisdeeeeeooo, o turíbulo queimando incenso, ora pro nobis, ora pro nobis tantum ergumsacramentumveneremurcernui. Meus irmãos, o nosso é um país católico..." (p.40).

Há predominância de imagens, ludismo à página 38, intitulado "JOSÉ ACODOU" seguido de um esquematismo para explicar o sonho, com mistura de estilos e ao final "JOSÉ SONHOU QUE, DORMIA". Seguido pela descrição e ou apresentação do esqueleto, através do recurso metalinguístico. O próximo título "ADEUS, ADEUS" traz à tona a violência praticada a quem pesquisa, o exílio, o confisco dos livros e o lema daqueles que temem perder o poder, nas palavras a declaração do presidente: "Quando a ciência subverte o homem e corrompe, é melhor ter um país sem ciência, atrasado", numa alusão ao cientista Marcondes Reis que conseguira sair do país ajudado pelos amigos e prosseguir as pesquisas na Universidade Patrice Lumumba, após perder a cátedra e ter sua casa invadida, os filhos ameaçados e os livros confiscados. (BRANDÃO, 1975, p. 41). Assim, justifica-se o ecletismo estilístico presente no romance.

O Discurso Direto, ou seja, na reprodução da fala do personagem, José tem voz ao dialogar com o funcionário de uma agência, a qual seleciona perfis que pretendem constituir um lar, discute suas características físicas e psicológicas ao selecioná-las para o anúncio: "VISÃO"- "a águia gigantesca a levar José para o seu ninho, na cabeça da América". Segue o anúncio:

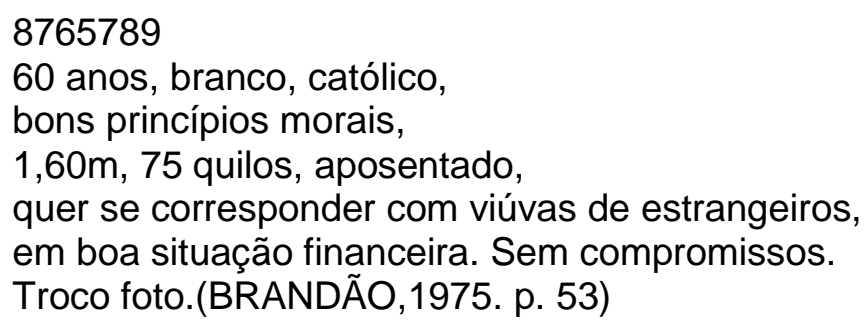

Enfim, é apresentado a José uma sugestão de leitura editada pela agência e é em forma de simulacro, pelo qual ele simula ir efetuar uma ação, mas tenciona não a praticar:"Sucata: [...]NÃO DEIXEM SABER QUE ESTES LIVROS EXISTEM AQUI/ VOCÊ JÁ ESTEVE UMA VEZ NAS INVESTIGAÇÕES.../PÁRA JOSÉ DE LER ESSES LIVROS: sucata" (BRANDÃO,1975,p.53).

A linguagem empregada na narrativa fragmentada é como forma de criticar os valores culturais, sociais, econômicos, políticos existenciais da sociedade consumista que destrói as classes marginalizadas. As questões referentes ao 
homem, ao mundo mesclam-se aos assuntos que causam dificuldades de compreensão e ou assimilação ao leitor. Instala-se no texto um jogo entre o real e o irreal, havendo diluição do tempo e do espaço. "A simulação é infinitamente perigosa, pois deixa sempre supor, para além do seu objeto, que a própria ordem e a própria lei poderiam não ser mais que simulação." (BAUDRILLARD, 1991, p.30).

Ao supor algo a simulação torna-se infinitamente mais perigosa. Os simulacros são experiências, formas, códigos e objetos sem referência, que se apresentam mais reais do que a própria realidade, são hiper-reais.Conforme o autor: "[...] a simulação já não é a simulação de um território, de um ser Referencial, de uma substância. É a geração pelos modelos de um real sem origem nem realidade: hiper-real" (BAUDRILLARD, 1991. P. 08).

Assim o filósofo, sociólogo e francês entendia nossa condição como a de uma ordem social na qual os simulacros e os sinais estão, cada vez mais, constituindo o mundo contemporâneo, qualquer forma de distinção entre o "real" e o "irreal", tornase impossível. Ademais, vive-se numa nova fase da história organizado em torno de simulacros e simulações, por isso, transforma nossas experiências, destrói sentidos e significações, implica no conceito de realidade. A explanação é para atender a análise do caso Zero, romance incomum, extremamente experimental na Literatura, pois ele intenta retratar o caos tanto no conteúdo quanto na forma, evidente pelos tipos de texto que se apresentam ao longo da narrativa que criam uma paisagem do Brasil e do contexto histórico-social evidente na passagem a simulação, a paisagem da violência:
A NÃO EXECUÇÃO
Cala a boca esqueleto.
O que fala sem parar. E continua quando o chefe manda calar [...]
Vão me matar. Estou com medo. Estou com frio. Não deveria ter medo. la ser assim, alguém me pegaria. Só tenho que pensar: vão me matar. De jeito nenhum. Antes eu pensava: o que será que vou pensar na hora em que me pegarem. Não penso nada, só tenho medo. Se ao menos eu apagasse logo. Mas vão me torturar. Vão querer que eu diga coisas. Que nem sei. [...] cinturões de bala atravessando o peito como faixa: Miss Violência, Miss Assassinato, Miss Sangue, Miss Tortura, Miss Agonia, Miss Espancamento, Miss Mutilação, Miss Carrasco.
? Adiantou a minha violência.
Adiantou. [...] Vivi 130 anos diante de cada homem aquém apontei o revólver. (BRANDÃO, 1975, p. 238) 
Um exemplo de simulacro hiperreal. Na concepção de Baudrillard (1991), o ato de fingir não altera a realidade. É uma farsa na qual o ator principal está consciente de sua encenação. Pode-se fingir para ele, a realidade pós-moderna é um simples reflexo e simulação daquilo que outrora pôde ser chamado de real (verdade).Ou seja, o que é atualmente apresentado como verdade é apenas uma simulação de algo que foi real.Ainda sobre o poder:

Como é o facto de o poder já não existir, em suma, senão para esconder o que não existe[...] Completamente expurgado da dimensão política, o poder depende, como qualquer outra mercadoria, da produção e do consumo de massas. Todo o brilho desapareceu, só se salvou a ficção de um universo político (BAUDRILLARD, 1991, p. 38).

Valores concebidos como sólidos, estáveis, formas de dominação, de controle, modificam-se, desmancham-se para adquirir novos sentidos, algo em processo, jogo das identidades, maneiras diferentes de agir em casa, no trabalho, é mais oportuno desapegar-se das estruturas. A forma fragmentada de Zero expressa o caos do momento histórico em que o homem e o mundo estão diluídos no espaço. Essa diluição está presente já na segunda página do livro, que vem dividida em duas colunas, estes fragmentos, no livro, aparecem divididos em colunas à esquerda e à direita, respectivamente:

\footnotetext{
Jose mata ratos num cinema poeira. Um homem comum, 28 anos[...] CADA RATO TEM UM PREÇO

Nove horas, José veste o macacão, calça as botas de borracha e instala a aparelhagem de tambores e tubos plásticos. Aciona a manivela e

NOME: cosmo ou universo.

CARACTERÍSTICAS: contém os "corpos" celestes e o espaço em que eles se encontram [...]

PESO: [...]

FORMAÇÃO: [...]

FORMA DE VIDA: (BRANDÃO, 1975. p. 11).
}

Esse fragmento, que no livro aparece dividido em duas colunas, representa a própria divisão da relação espaço-personagem: de um lado, a descrição de José; do outro, as informações técnico-científicas sobre o universo. Ao compararmos as medidas grandiosas do universo, à vida de José, observa-se a mediocridade de sua 
vida. Dessa maneira, ele se torna ainda mais insignificante. Como se observa, esse excerto representa a desumanização, a qual permite que fosse violentado.

Assim, o fazer narrativo do romance, calcado em fragmentos, além de ser uma resposta ao paradoxo social, é algo que enfatiza a ideia de que o desenvolvimento da série literária se faz no interior da história, dialogando com todas as coordenadas, nas características como a desarticulação do enredo, a fragmentação, a descontinuidade, a justaposição e mesmo o apagamento da figura do narrador. Algumas dessas marcas podem ser evidenciadas a seguir:

\begin{abstract}
O PROGRESSO DA CIÊNCIA
"Nossa equipe de cientistas descobriu que as galinhas mais felizes botam ovos mais saborosos.". (Interrompemos esta nota para uma comunicação oficial) TEMPERATURA INSTÁVEL, SUJEITA A CHUVAS E TROVOADAS No país há calma.

O congresso foi fechado. Prisão de cem deputados federais e estaduais. Aumentados os vencimentos dos militares. A polícia recebeu gases estrangeiros para os trabalhos de repressão.

Continuam, todas as noites, nas praças principais de todas as cidades, a queima de livros ao som de hinos religiosos. (BRANDÃO, 1975, p. 157-158).

O PROGRESSO DA CIÊNCIA

Além de aplicar uma dieta, os cientistas deixaram as galinhas ao ar livre, esgaravatando aqui e ali, em busca de minhocas ou qualquer alimento que melhor lhes apetecem. Elas se tornaram mais felizes com isso, fazendo ovos mais saborosos, ao contrário dos ovos postos pelas galinhas (BRANDÃO, 1975, p. 157-158).
\end{abstract}

Nesses fragmentos, de acordo com Calegari (2011), são como que reproduzidas notícias referentes ao dia 13 de dezembro de 1968, data do Al-5. O título Temperatura instável, sujeita a chuvas e trovoadas foi retirado da capa do Jornal do Brasil do dia seguinte, 14 de dezembro, quando o jornal - claramente censurado - falava do clima do país, apontando "Tempo negro. Temperatura sufocante. O ar está irrespirável. O país está sendo varrido por fortes ventos" (DALCASTAGNÈ, 1996, p.72). O clima do romance, a rigor, também não é dos mais agradáveis. Poderia ser definido como a calmaria que precede a tempestade. $O$ título da obra ratifica essa ideia: zero é um círculo fechado, que encerra, prende e sufoca.

A estrutura fragmentada do livro faz referência indireta ao período histórico vigente. Em meio à censura e às práticas repressivas, a população não tinha uma 
visão total e abrangente da realidade. No livro são misturados recursos que marcam a fragmentação na narrativa: desenhos, fórmulas publicitárias, fotocópias de recortes de jornais, códigos visuais de revistas em quadrinhos, avisos, flashes de informação, anúncios classificatórios de jornal. Essa estrutura objetiva criticar os valores da sociedade capitalista que torna o ser humano objeto de manipulação, sem perspectivas, sem individualidade - dinâmica das relações no mundo globalizado em que, embora o capitalismo pregue o contrário e assim se estabeleça pela lei da oferta e procura, todos têm a mesma importância na hierarquia valorativa para que se obtenha o produto final.

A diagramação do romance Zero é inusitada, semelhante a um almanaque, com diversas tipografias, para cada gênero de texto e para cada tipo de efeito. Apresenta um cenário constituído por diversas histórias que retratam no cotidiano a violência e por apresentar na sua tessitura, traços formais até então inusitados que representam o seu momento histórico-cultural, que na acepção de Pellegrini (1996, p.125): "lança no mercado romancistas novos e consolida o conto como gênero de maior repercussão". Bem como o surgimento do romance-reportagem, que prioriza a objetividade jornalística na narração que atendia ao desejo dos relatos e notícias que não podiam veicular devido à censura. Essa necessidade de falar e de dialogar com o jornalismo e a ficção consolida-se como tendência dos anos de repressão. A narrativa de ficção reproduzindo aquilo que não poderia ser veiculado no jornal e que impedia as pessoas de lutarem por seus ideais na sociedade em função do medo também é dito através do romance autobiográfico.

\section{Considerações Finais}

Zero publicado primeiramente na Itália em 1974, depois no Brasil, é um retrato de sua época diante da Ditadura Militar Brasileira (1964-1985), período este marcado pela censura cultural, pelo controle dos indivíduos no que eles tinham de mais íntimo. Um romance em que o protagonista, José Gonçalves, homem comum, que mata ratos num cinema vagabundo, casado com Rosa, que a conhecera através de uma agência matrimonial, vive uma relação com inúmeros momentos de amor e 
ódio e vai se tornando inconformado com sua situação, com seu mundo até tornarse criminoso. A partir de então o personagem é o símbolo do inconformismo, do caos.

Pesquisador como Ginzburg (2012), na crítica literária, acredita que é aspecto da modernidade a naturalização da violência e a acentuação da construção negativa do sujeito. Nesse contexto, a literatura fornece subsídios - tema e forma - para uma espécie de resistência que surge com o objetivo de pensar sobre os direitos humanos. É no meio literário, a exemplo de Brandão (1975), encontram-se escritores que utilizam a violência como tema e recurso estético, bem como apresentam outras faces da narrativa moderna na violência atuante na sociedade. Por isso, ao relacionar forma e conteúdo na obra, justifica-se essa opção metodológica pela análise e interpretação comparativa dos elementos constitutivos do personagem José e as manifestações da violência.

Acerca do fazer narrativo do romance descobriu-se que com o uso de recursos metafóricos da linguagem que a intenção crítica que o autor realiza através da ironia, da sátira, da problematização do tempo do espaço, a presença de características contraditórias do personagem com livre associação de ideias e ou fluxo da consciência - ser ou não ser, confunde-se com o real e o irreal. Assim como as prisões, as torturas e assassinatos de pessoas que se opuseram de qualquer maneira ao regime militar, diante do inconformismo e do caos. Pode-se observar neste excerto que representa a personalização da narrativa:

Do chefe da POPO / Polícia Política / ao chefe da POFE: "Respondendo a sua $\mathrm{Cl}$ confidencial de 31 do corrente informo que nenhum preso foi torturado nas celas deste departamento, desde o início do novo governo. [...] Detalhe: Veja-se a frase "torturado nas celas". Realmente, nas celas não houve torturas. Havia uma sala para isso. Do chefe da POFE ao chefe da POSU (Polícia de Supersegurança): "Fechar os jornais que denunciaram torturas na POPO. Processá-los." Pergunta irônica que certamente eu não irei fazer ao chefe da POFE: [...] (BRANDÃO, 1975, p. 246).

Entre o real e o irreal há uma confusão também apresentada na primeira frase do romance Num país da América Latíndia, amanhã (p.10), a informação temporal é diluída entre o jogo do real e o irreal. O título Zero remete à ideia de negação e ao princípio do nada a que se reduz a realidade. Da mesma forma em que o 
personagem José também é reduzido à ideia de nada, de zero. Por isso, trata de um ciclo que já fora concluído e sugere a reconstrução de uma época. Esses recursos em pedaços, através de imagens, de mistura de estilos, representam um ludismo, desarmonia intencional na constituição do romance. Desse modo, as peculiaridades de composição da obra representam a compreensão da realidade diluída, que questiona a forma do real, através desta ruptura com a forma tradicional das narrativas.

O personagem José dentre outros vive em uma megalópole, em um país qualquer da América Latíndia. Talvez seja São Paulo, onde os indivíduos vivem na mediocridade, massacrados pela repressão, tortura e uma terrível censura que se instalara neste espaço. Portanto, o caos toma conta e a fragmentação do sujeito se traduz na fragmentação da linguagem do romance que causa estranheza em sua forma. Assim, percebe-se que a vida na cidade se torna cada vez mais caótica, é a imagem do caos no romance.

A produção literária nas décadas de 60,70,80, abordara críticas ao regime militar, através de uma linguagem simbólica e da fragmentação formal. Que na acepção:

[...] além de procurar atingir a dimensão metafísica das realidades humanas vitais - desmascarando ilusões, tabus, conceitos, preconceitos e condicionamentos - e de abordar temas e problemas socioculturais - denunciando manipulações ideológicas, informações falsas, apreensão e violência - e situar a literatura dentro do deviratribuindo-lhe valor histórico, preocupa-se com a sua apresentação formal, ajustando-se a meios mais eficientes de traduzir e expressar suas metas criativas (MACHADO, 2009, p. 48).

Assim, essa produção não inova somente na forma e no conteúdo. Ambos são utilizados simultaneamente de forma criativa e crítica. A estrutura fragmentária faz uma referência indireta ao período histórico vigente. As práticas repressivas e a censura impediam as pessoas de lutarem pelos seus ideais, em função da realidade violenta e injusta. Por isso, em Zero a relação de José dá-se através da violência na sua descrição e na de seu trabalho, estabelece comunicação com seu tempo, estão presentes os fragmentos de um país violento, bem como as consequências do regime autoritário e a formação da sociedade sustentada por práticas violentas.

A literatura nacional, apesar da influência europeia, possui vínculos estreitos com a vida nacional. A autenticidade que marca o pensamento brasileiro. A ditadura 
censurou, perseguiu artistas e exilou intelectuais. Para fugir das malhas da censura, nossos escritores, então se utilizaram de um jogo de metáforas e símbolos que transmitia uma crítica às estruturas de poder no Brasil.

Neste cenário surgiu o romance-reportagem, que se utilizando de técnicas narrativas denunciavam a violência, o arbítrio policial e militar dos anos de chumbo. Além da censura causada pela ditadura. Essa nova conjuntara traz em consequência a implantação de um capitalismo selvagem. Nesse espaço nasce o romance pós-moderno: perda de identidade e da centralidade do sujeito e desobediência aos cânones literários. Embora lançados por uma indústria cultural embrionária, tornaram-se best-sellers, além dos inúmeros relatos autobiográficos de ex-exilados acerca das torturas, dramas que se passaram nos "porões" - salas de tortura descritas em Zero, da ditadura militar.

A obra de Ignácio de Loyola Brandão é o resultado formal da realidade diluída e desestruturada, sua linguagem vai de encontro aos valores sustentados pelo autoritarismo dos anos 1970. Por isso, resiste aos valores culturais da sociedade de consumo e opõem-se ao romance de estrutura convencional, daí o uso da montagem, o desrespeito às regras convencionais, a fragmentação da narrativa, a desordem vocabular, a informalidade, o recurso às técnicas cinematográficas e televisivas. Além disso, em seu enredo evidencia-se, de modo profundamente crítico, a opressão tanto social quanto ideológica.

Pelo que foi apresentado, o romance em questão propõe uma avaliação do momento histórico da época de sua produção. Bem como de seus elementos temáticos, a forma de sua composição não é ordenada o que nos permite dizer que representa o período caótico pós-64. O regime autoritário abala as estruturas do indivíduo, a dificuldade de expressão é problematizada através da linguagem e esta particularidade surge por influência da conjuntura histórica.

\section{REFERÊNCIAS}

BAUDRILLARD, Jean. Simulacros e simulação. Lisboa: Relógio d’Água, 1991. 
BRANDÃO, Ignácio de Loyola. Zero. São Paulo: Clube do Livro, 1975.

CALEGARI, Lizandro Carlos. Uma estética fragmentária: a perspectiva crítica em Zero e a organização da linguagem literária. Revista Interdisciplinar. v. 13: Ano VI. jan-jun de 2011. p.165-175.

DALCASTAGNĖ, Regina. O espaço da dor: o regime de 64 no romance brasileiro. Brasília: UnB, 1996.

GINZBURG, Jaime. A violência constitutiva e a política do esquecimento. In:

Crítica em tempos de violência. São Paulo: Edusp, Fapesp, 2012. p. 217-238.

MACHADO, Roberto. A Linguagem Literária e o de fora. In: Deleuze, a arte e a filosofia. Rio deJaneiro: Jorge Zahar, 2009.

PELLEGRINI, Tânia. A narrativa brasileira contemporânea: emergência do pósmodernismo. Revista Letras. Campinas, n. 13, v.1/2, p. 8-59, dez., 1994.

PELLEGRINI, Tânia. Gavetas vazias: ficção e política nos anos 70. São Carlos, SP: EDUFSCAR, 1996. 